\title{
AN OVERVIEW OF RESEARCH DESIGNS RELEVANT TO NURSING: PART 2: QUALITATIVE RESEARCH DESIGNS
}

\author{
Martha Driessnack ${ }^{1}$ \\ Valmi D. Sousa ${ }^{2}$ \\ Isabel Amélia Costa Mendes ${ }^{3}$
}

Driessnack M, Sousa VD, Mendes IAC. An overview of research designs relevant to nursing: part 2: qualitative research designs. Rev Latino-am Enfermagem 2007 julho-agosto; 15(4):684-8.

This second article of the series "An Overview of Research Designs Relevant to Nursing" presents qualitative research designs. Phenomenological, ground theory, ethnography, narrative inquiry, and other related qualitative-related research methodologies are described. In addition, the importance of qualitative research as groundwork for quantitative studies is discussed. This link between qualitative and quantitative research is fundamental to promote evidence-based nursing practice.

DESCRIPTORS: nursing research; qualitative analysis; methodology; nursing

\section{REVISIÓN DE DISEÑOS RELEVANTES PARA ENFERMERÍA: PARTE 2: DISEÑOS DE INVESTIGACIÓN CUALITATIVA}

Este segundo artículo de la serie de "Revisión de los Diseños de Investigación Relevantes para Enfermería" presenta los diseños de investigación cualitativa. Son descritas metodologías fenomenológicas, teoría fundamentada en los datos, etnografía, investigación narrativa entre las principales. Así mismo se discute la importancia de la investigación cualitativa como base para estudios cuantitativos. Esta conexión entre investigación cualitativa y cuantitativa es fundamental para promover la práctica de enfermería basada en evidencias.

DESCRIPTORES: investigación en enfermería; análisis cualitativo; metodología; enfermería

\section{REVISÃO DOS DESENHOS DE PESQUISA RELEVANTES PARA ENFERMAGEM: PARTE 2: DESENHOS DE PESQUISA QUALITATIVA}

Este segundo artigo da série "Revisão dos Desenhos de Pesquisa Relevantes para Enfermagem" apresenta desenhos de pesquisa qualitativa. São descritas metodologias fenomenológicas, teoria fundamentada nos dados, etnografia, investigação narrativa, entre outras. É também discutida a importância da pesquisa qualitativa como base para estudos quantitativos. Essa conexão entre pesquisa qualitativa e quantitativa é fundamental para promover a prática de enfermagem baseada em evidência.

DESCRITORES: pesquisa em enfermagem; análise qualitativa; metodologia; enfermagem

\footnotetext{
${ }^{1}$ PhD, APRN, BC, Postdoctoral Research Fellow in Clinical Genetics, College of Nursing, The University of Iowa, United States of America, e-mail: marthadriessnack@uiowa.edu; ${ }^{2}$ PhD, APRN, BC, Assistant Professor, College of Health and Human Services, The University of North Carolina at Charlotte, United States of America, e-mail: vdsousa@uncc.edu; ${ }^{3} \mathrm{PhD}$, RN, Full Professor, University of São Paulo at Ribeirão Preto College of Nursing, WHO Collaborating Centre for Nursing Research Development, Brazil, CNPq Researcher 1A, e-mail: iamendes@eerp.usp.br
} 


\section{INTRODUCTION}

As stated in the first article of the series "An Overview of Research Designs Relevant to Nursing Part 1 - Quantitative Research Designs"(1), a research design guides the planning and implementation of a study to adequately answer questions or test hypotheses posed for investigation. However, to answer questions or test hypotheses adequately, researchers must have a good understanding of both quantitative and qualitative research designs relevant to nursing. While the majority of nursing research around the world has been primarily quantitative in nature, current nursing research is increasingly being conducted using qualitative research designs. Thus, the focus of this article is to expand on the quantitative research designs presented and discussed in the first article in this series, by introducing relevant qualitative research designs and how they can be used in the field of nursing.

\section{RELEVANT QUALITATIVE RESEARCH DESIGNS}

Qualitative research designs are "rooted in the naturalistic paradigm"(1). This paradigmatic approach to research differs from the deterministic philosophy that underlies the quantitative, postpositivist paradigm. In contrast to post-positivism, a naturalistic philosophy asserts that reality is subjective, rather than objective, because there is not one single reality, but multiple realities and the knowledge gained is only relevant within that particular situation or context ${ }^{(2-3)}$.

In qualitative research, the research process is inductive, rather than deductive, and begins with broad exploratory aims that provide a focus for study without pre-empting which aspects of the experience may be deemed important or relevant. Researchers use qualitative research designs when there is a gap in knowledge or when little is known about a particular phenomenon, experience, or concept ${ }^{(1)}$. Qualitative researchers study people in natural settings and attempt to make sense of, or interpret, the meanings people attribute to their experiences ${ }^{(4)}$. These natural settings, which are often referred to as the field, stand in stark contrast to the clinical and/or laboratory settings used in quantitative designs that are typically designed to exert more control over the study and its variables ${ }^{(5)}$
Qualitative research is used to explore healthrelated or illness-related experiences or groups where little is known, or the when current understanding seems inadequate ${ }^{(6)}$. It is also used to gain new insights into previously researched phenomena, groups, experiences, or concepts. It often precedes quantitative work, but may be used concurrently or sequentially ${ }^{(3,7)}$. This interplay between and among qualitative and quantitative designs is referred to as mixed or multiple methods and will be the focus of the third article in this series.

The most distinctive characteristics of qualitative research are that the researcher is also considered an instrument for data collection and resultant data are primarily words or narrative descriptions rather than numbers. Instead of the numerical comparisons and statistical inferences used to sort quantitative data, qualitative data are sorted into themes, concepts, and/or theories, identified and synthesized from detailed descriptions of experiences and social processes shared by the participants. While quantitative researchers work with a few variables and many subjects, qualitative researchers rely on a few subjects or participants and many variables ${ }^{(7-8)}$.

In qualitative research, participants are purposively selected for their experience with the phenomena of interest as opposed to a random selection or sampling from a larger population. The data from selected participants are considered rich in detail and are often referred to as dense or thick descriptions. Typical sample sizes vary from few up to 30 participants. This is quite different from quantitative samples that often require larger number of participants, guided by statistical power analyses. The power in qualitative research is in the richness of description and detail of specific lived experiences, social processes, cultures, and narrative accounts.

The methods used in qualitative designs are less structured than in quantitative designs and primarily include multiple in-depth interviews, ongoing participantobservation, written diaries, narrative descriptions, and focus groups. The four types of qualitative research designs most often used to conduct nursing research include: 1) phenomenology, 2) grounded theory, 3) ethnography, and 4) narrative inquiry.

Phenomenology

The purpose of phenomenological research is to describe specific phenomena of interest as they 
are lived and experienced by individuals. The focus of phenomenological studies is on understanding what an experience means within the context of people's lives. This is referred to as capturing the lived experience. For example, a research question for this approach might be "What is the experience of teens living in a family at genetic risk for Huntington disease?" The only reliable sources of information to answer this type of inquiry or question are the people experiencing the phenomena. In this example, teen participants would be sought whose parent or grandparent had tested positive or had symptoms of Huntington disease.

To select a sample for a phenomenological study, the researcher purposively selects individuals or groups that have experienced the phenomenon. Inclusion and exclusion criteria are established based on the focus for study. Estimating the number of participants depends on the amount and quality of information elicited from each participant, the scope of the study, the nature of the topic, and the number of interviews per participant ${ }^{(9)}$. In a focused study, with a clearly defined topic and limited scope, a relatively small sample size (10 or fewer participants) is required. However, if each participant is interviewed only once and the amount of information limited, large numbers (up to 60 participants) are sought. The key is to reach saturation of data. Saturation is the state where no more new data of importance to the study emerges and the elements of all of the themes, concepts, and theory are accounted for ${ }^{(10)}$.

Grounded theory

Researchers use a grounded theory design when they are interested in phenomena involving the social processes underlying human experiences and behavior $^{(5)}$. For example, a research question for this approach might be "How do children cope following the death of a sibling?" In this example, children would be interviewed and asked questions, as well as their parents and, perhaps, their schoolteachers. The different concepts and patterns of coping that emerge from the analysis of the data are then synthesized into a theory to serve as a guide for further understanding or testing. The main idea is that the theory of how children cope emerges from the descriptions of those experiencing the phenomenon, not from ideas from those who have not. The aim of a grounded theory approach is the generation of theory that comes from, or is "grounded" in, the $\operatorname{data}^{(10)}$.

The primary characteristics of grounded theory designs are theoretical sampling and the constant comparison of data with emerging categories $^{(3)}$. Data collection and analysis occur simultaneously and each piece of new data is constantly compared and contrasted with previously identified concepts $^{(5)}$. Sample sizes tend to be larger in grounded theory designs, when compared to other qualitative designs, because of need for theoretical sampling. Theoretical sampling means that the selection of participants is directed by the emerging analysis $^{(6)}$. In other words, the researcher begins with a focused sample, but as different concepts emerge, the researcher seeks out additional participants based on further understanding of these concepts. This process often includes the search for outliers and negative cases so the full range of possible experiences or a full understanding takes place. Theoretical sampling continues until the researcher is satisfied that the theory synthesized from the data and concepts are reflective of the social process under study.

Ethnography

Researchers use ethnography as a research design when they are seeking a deeper understanding or description of a specific culture, group, or community ${ }^{(10)}$. Ethnography involves experiencing, most often by participant observation, enquiring, through interviews and oral histories, and examining, the study of cultural documents and artifacts. Most of the time, ethnography is equated with the extended immersion of the researcher in the culture, group, or community under study. This is often referred to as fieldwork and the extensive notes taken by the researcher are referred to as field notes. Immersion in the field helps the researcher identify key informants, customs, and artifacts that are so enmeshed in the group being studied that they would probably not be identified by simple interview.

Although ethnography is the research design most often thought of when studying culture, the word culture can be interpreted in many ways. Culture can be defined as the way of life of a group - learned behaviors that are socially constructed and transmitted ${ }^{(10)}$. Researchers can use ethnography to explore the culture of nursing, of nursing homes, 
academia, and/or politics. Each of these cultures has its own way of communicating, its own customs, rites of passage, and artifacts. This broader interpretation of ethnography and culture is being used more often in research today.

Using ethnography, the researcher's responsibility is to describe the unique and distinctive processes or rules of behavior of the subculture or culture with the primary aim of further understanding and communication. The important concept in ethnographic research design is the emphasis on obtaining an emic, rather than etic, perspective. An emic perspective is the cultural member's, insider's, or native's point of view or perspective ${ }^{(9)}$. This perspective is essential as it prevents the imposition of the values and beliefs of researchers and other outsiders. The outsider, or etic, perspective has been prevalent for too long both in health care and in research(10). Ethnography is often very time consuming and intense for the researcher as data collection involves ongoing immersion in the culture and participant observation.

Narrative inquiry

Narrative inquiry is a broadly determined and interpreted research design that involves individual narrative accounts and the interpretation of their meaning ${ }^{(10-11)}$. Narrative accounts can be obtained from a number of groups including patients, family, and caregivers. In narrative inquiry, the researcher studies the lives and experiences of individuals or groups by asking them to talk about or story their experiences. The resultant narratives are analyzed within and across individuals and then re-told or restoried by the researcher ${ }^{(3)}$. The primary aim of narrative inquiry is to listen and question earlier assumptions. For example, children are typically understood through adult proxy, usually their parents. When children themselves are asked about their experiences, their narrative accounts are often quite different. The same can be said of patients and others in the same room.

Individuals are purposively selected for participation in narrative inquiry studies based on the research focus and criterion under study. The numbers of participants vary and depend on the overall focus and scope of the study and the amount of information gained from each narrative account. Narratives are analyzed individually and then across participants until a meta-narrative or overall story is synthesized and the re-told by the researcher.

Narratives can be examined for their content and/or structure. When examined for content, the researcher looks at what is said and the analysis appears very similar to the thematic analysis used in phenomenology. However, when narratives are examined for their structure, the researcher looks at how the story is constructed and told. Through this process, researchers examine what details are prioritized, reiterated, emphasized, and/or left out looking not so much at the story itself, but at why the story was told in this particular way.

\section{OTHER QUALITATIVE-RELATED RESEARCH METHODOLOGIES}

By themselves, critical theory and participatory action research do not represent specific qualitative research designs. Researchers who use these qualitative-related methodologies often approach knowledge based on qualitative assumptions. Critical theory research is concerned with promoting change and empowering human beings by critically evaluating the social phenomena that place constraints on them. Typically, researchers use critical theory to inform or work for change and emancipation of marginalized or silenced groups from the identified social phenomena being studied ${ }^{(2-3)}$. Participatory research or participatory action research $(P A R)$ emerged from critical theory and is focused on bringing about change in practice by changing the research process ${ }^{(2)}$. PAR involves both researchers and participants as co-researchers or participants ${ }^{(2,6)}$. $P A R$ is usually undertaken to create an action agenda for change with marginalized or previously silenced groups $^{(3)}$. Other qualitative-related methodologies may also include historical research and philosophical inquiry. Historial research examines data from the past while philosophical inquiry examines issues from all perspective regarding values, ethics, and the science $^{(2)}$

\section{CONCLUSION}

The selection of a research design begins with the research question and the phenomena being studied. Just as different types of quantitative research 
designs exist to answer different quantifiable research questions, different qualitative designs exist to answer questions about the many different conditions of people's health, illness, and life experiences. Understanding the purpose of each research design assists nurses in selecting the best design for answering their research questions. Focusing the research question and enlisting the best research design to answer that question, is the first and most important step in conduction scientifically sound research - whether it be qualitative or quantitative. Each builds the other and enriches nursing science and practice.
Scientifically sound, qualitative research studies often serve not only as groundwork for theory development but also for the design, implementation, and refinement of quantitative studies. While rigorous quantitative research studies often serve to identify the gaps in the literature and little understood phenomena in need of qualitative study. The ongoing interaction between these two approaches to knowledge leads to the accumulation of a broad array of research findings to help move nursing from tradition-based to an evidence-based practice. In the next article, the combination or mixing of designs within one research study will be introduced.

\section{REFERENCES}

1. Sousa VD, Driessnack M, Mendes IAC. An overview of research designs relevant to nursing: Part 1: quantitative research designs. Rev Latino-am Enfermagem 2007 maiojunho; 15(3): 503-7.

2. Burns N, Grove SK. The practice of nursing research: Conduct, critique, and utilization. 5th ed. St Louis: Elsevier;2005.

3. Creswell JW. Research design: Qualitative, quantitative, and mixed methods approaches 2nd ed. Thousand Oaks: Sage Publications; 2003.

4. Denzin NK, Lincoln YS. Handbook of Qualitative Research. 2nd ed. Thousand Oaks: Sage Publications; 2000.

5. Vishnevsky $\mathrm{T}$, Beanlands $\mathrm{H}$. Interpreting research in nephrology nursing: Qualitative research. Nephrol Nurs J 2004; 31(2): 234-8.

6. Richards L, Morse JM. User's Guide to Qualitative Methods. 2nd ed. Thousand Oaks: Sage Publications; 2007.

7. Ailinger RL. Contribuições da pesquisa qualitativa para a prática de enfermagem baseada em evidências. Rev Latinoam Enfermagem maio-junho 2003;11(3):275-279.

8. Creswell JW. Qualitative Inquiry and Research Design: Choosing Among Five Traditions. Thousand Oaks: Sage Publications; 1998.

9. Morse JM. Determining sample size. Qual Health Res 2000; 10(1): 3-5.

10. Holloway I, Wheeler S. Qualitative Research in Nursing. 2nd ed. Oxford: Blackwell Publishing; 2002.

11. Silva DGV, Trentini M. Narrations as a nursing research technique. Rev Latino-am enfermagem 200 2maio-junho; $10(3): 423-32$. 